\title{
GOLDEN-HAR SYNDROME
}

\section{Maj V MATHUR ${ }^{*}$, Lt Col RK MISHRA ${ }^{+}$}

MJAFI 2000, 56 : 231-232

KEYWORDS: Branchial arches; Epibulbar dermoid; Oculo-auriculo-vertebral dysplasia, Preauricular appendages.

\section{Introduction}

$\mathbf{G}$ olden-Har Syndrome (Oculo-auriculo/vertebral dysplasia) is a rare syndrome of complex structures developing from first and second branchial arches during blastogensis.

The occurrence of Golden-Har syndrome is sporadic and no mode of inheritance has been established. However, Tsai and Tsai [1] have reported this syndrome in three consecutive generations of a family. There have been no reports about any incriminating drugs or environmental factors. We herein present a classical case of this syndrome.

\section{Case Report}

An 18-year-old boy presented to the OPD of this hospital with mass in left eye and skin tags in front of left ear since birth. The condition was constant since birth. No family history of similar defects was present. Clinical examination revealed an Epibulbar Dermoid in left eye and two preauricular appendages in front of left ear (Fig-1). The eyeballs and ears were normal in all other respects. X-Ray of cervical spine revealed spina bifida of C-5 \& $\mathrm{C}-6$ vertebrae. There was no neurological deficit. (Fig-2). Excision of epibulbar dermoid and preauricular appendages was done under local anaesthesia in a combined effort by the Eye and ENT specialists. Histopathology report confirmed the clinical diagnosis (Fig-3).

\section{Discussion}

Golden-Har syndrome consists of ocular, auricular and skeletal anomalies.

Amongst ocular features, epibulbar dermoids are

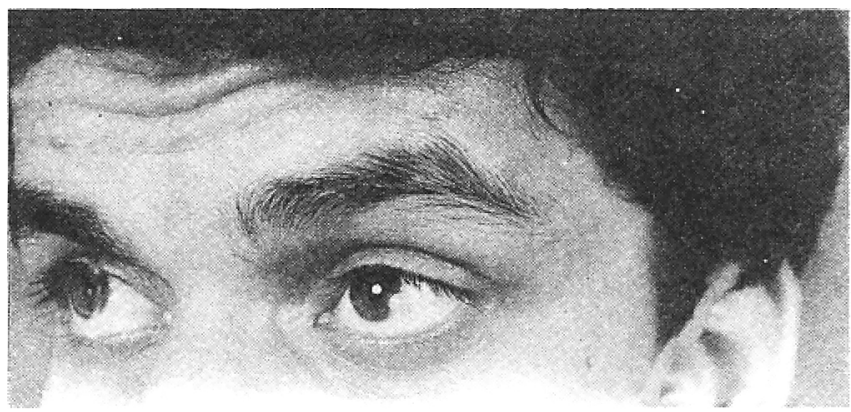

Fig. 1: Pre-operative photograph of Golden-Har Syndrome showing left sided epibulbar dermoid and accessory preauricular skin tag. the commonest. These are present in $75 \%$ of the cases and may be bilateral. They are classically located in inferio-temporal quadrant. These are choriostomas i.e. nest of normal tissue in abnormal places. Lipodermoids are present in less than 50\% of cases. Dacryocystitis has also been reported. The other rarer ocular

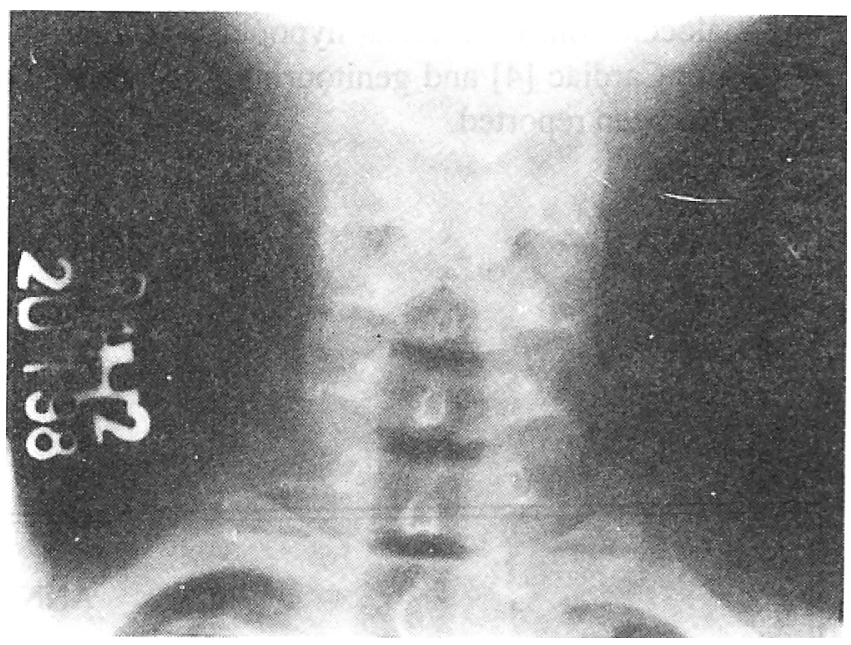

Fig. 2: Radiogram of cervical spine showing bifid C-5 vertebra.

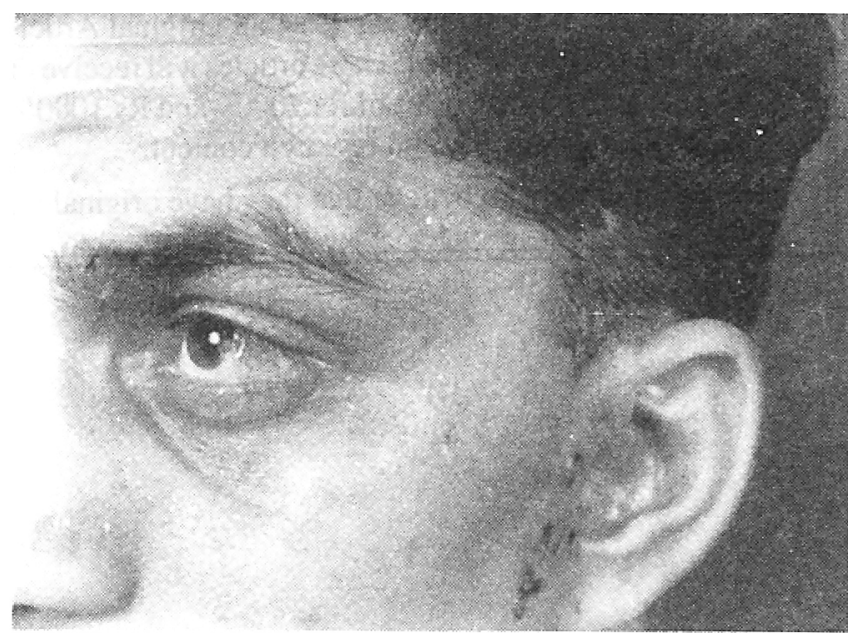

Fig. 3: Post operative photograph after successful excision of ocular dermoid and pre-auricular skin tags

\footnotetext{
"Graded Specialist (Ophthalmology), ${ }^{+}$Classified Specialist, (Otorhino laryngologgy), Military Hospital, Roorkee.
} 
afflictions are upper lid coloboma, microphthalmos, cataract, iris, anomalies, tilted disc, anophthalmos optic nerve hypoplasia and squint.

Amongst auricular afflictions, preauricular skin tags and accessory auricles are common. Anotia is rare and has been reported by Jaison and Batra [2].

Involvement of axial skeleton (vertebrae and ribs) has been observed in $24 \%$ of the patients in the largest series reported by Rollnic et al [3]. Spina bifida is the commonest and least severe of all anomalies. Hemivertebra, loss of vertebral arch and fusion of posterior elements of cervical vertebrae have also been reported.

Facio-dental anomalies include hypoplasia of malar bones, mandible and zygomatic arch, macrostomia, micrognathia, high vaulted cleft palate, bifid tongue and malocclusion. Hemifacial hypoplasia is a rare occurrence. Cardiac [4] and genitourinary [5] anomalies have also been reported.
Thus, this syndrome encompasses a very wide variety of disorders and anomalies, ranging from mild and inconspicuous to severe and debilitating. Mild varieties such as our case often go undetected till late adolescence and adulthood. Awareness of this condition will help in diagnosing more of such cases.

\section{REFERENCES}

1. Tsai FJ, Tsai CH. Autosomal dominant inherited Oculoauriculo-vertebral spectrum report of one family. Acta Paediatr $\operatorname{Sin} 1993 ; 34: 27-31$.

2. Jaison SG, Batra N. Goldenhar Syndrome with multiple additional anomalies. Indian J Ophthalmol 1996;44:42-4.

3. Rollnick BR, Kaye CI, Nagotoshi K, et al. Oculo-auriculovertebral dysplasia and variant:Phenotypic characteristics of 294 patients. Am J Med Genet 1987;26:361-75.

4. Mowison PJ, Mulholland HC, Craig BG, et al. Cardio Vascular abnormalities in the oculo-auriculo-vertebral spectrum (Golden-Har syndrome). Am J Med Genet 1992;44:425-8.

5. Ritchey ML, Narbeekj Huang et al. Urologic manifestations of Golden-Har Syndrome. Urology 1994;43:88-91. 